\title{
Evaluation of Gold-Coated Stainless Steel Bipolar Plates for Fuel Cell Applications
}

\author{
Ching Chiang Hwang ${ }^{1}$, Ing-Bang Huang ${ }^{2 *}$ \\ ${ }^{1}$ Department of Biotechnology, Mingdao University, Taiwan \\ ${ }^{2}$ *Department of Materials Science and Engineering, National Formosa University, Huwei, Yulin, 63201,
}

Taiwan (corresponding author)

\begin{abstract}
In this study, the computer-aided design and manufacturing (CAD / CAM) technology were applied to develop and produce stainless steel bipolar plates for DMFC (direct methanol fuel cell). Effects of surface modification on the cell performance were investigated. Surface modification of the stainless steel polar plate was made by electroless gold plating method. A DMFC consisting of gold coated stainless steel as anode and uncoated stainless steel as cathode was assembled and evaluated. The methanol crossover rate (Rc) of the proton exchange membrane (PEM) was decreased by about 43\%, the efficiency (Ef) of DMFC increased about $4.3 \%$ and amounts of methanol electro-oxidation at the cathode side (Mco ) were decreased by about $17 \%$, as compared to uncoated anode polar plates. These measurements were determined by the transient current and mathematical analysis.
\end{abstract}

Keywords: - Direct methanol fuel cell; Bipolar plates; Crossover rate; Methanol

\section{INTRODUCTION}

Bipolar plates, which are a type of multifunctional component, are one of the most important components in a PEMFC stack. The main functions of bipolar plates are to distribute and separate the cathodic and anodic reactant gases and to collect and transmit electric current. Usually, bipolar plates are fabricated from graphite, carbon composites and metallic materials, among which, metallic materials are most attractive owing to good mechanical properties and chemical stability, electrical conductivity and thermal conductivity and good machining properties. Metallic materials which can be recycled, such as titanium, aluminum, stainless steel, have been tested as possible candidates for bipolar plates. Unfortunately, metals are prone to corrosion and the resulting metal ions can readily migrate to, and poison, the membrane in a PEMFC environment. The dissolved metal ions can lower the ionic conductivity of the membrane and the performance of the PEMFC. Furthermore, any corrosion layer lowers the electrical conductivity of the bipolar plate, and increase potential loss because of higher electrical resistance. Hence, in order to act as suitable materials for bipolar plates, metals should have both very high corrosion resistance and high electrical conductivity $[1,2]$.

. In order to improve the corrosion resistance and electrical conductivity of the bare substrate, several coating material and processes have been proposed [1,2]. Gold (Au) has been studied as a coating material on stainless steel substrate by some researchers. Gold has high excellent corrosion resistance and electrical conductivity, and the use of very thin gold coating on bare substrate has proven very successful $[3,4]$.

Methanol crossover, which causes significant voltage loss and waste of fuel, is a serious problem in DMFC. Thus, it has attracted attention worldwide. Several methods have been used to measure methanol crossover in DMFC [5-10]. Pukrushpan et al. determined methanol crossover rates by continuously measuring the concentration of $\mathrm{CH} 3 \mathrm{OH}, \mathrm{CO}$ and $\mathrm{CO} 2$ in the exhaust gas of the cathode [5]. Narayanan et al. measured the methanol crossover rates by estimating the carbon dioxide content of the cathode exit stream. Crossover rates were reported as an equivalent current density of methanol oxidation [6]. Amphlett directly measured methanol flux rates across Nafion ${ }^{\circledR}$ membranes by an electrochemical method using a flooded electrolyte cell with two compartments separated by a membrane, with various concentrations of methanol [7]. A potentiometric method reported by Prakash et al. [8] showed that the slope (dE/dt) of the E versus t (time) curve is proportional to the crossover rate. The $\mathrm{CH} 3 \mathrm{OH}$ crossover rate was calculated from the time required to reach the equilibrium concentration of $\mathrm{CH} 3 \mathrm{OH}$ on either side of the polymer electrolyte membrane. Han and Liu determined the methanol crossover rates by measuring the carbon dioxide concentration at the cathode exit in real time [9]. Kin et al. proposed a relatively easy method for estimating the methanol crossover rate of a proton exchange membrane (PEM) and the efficiency of a direct methanol fuel cell (DMFC) by using current transient analysis [10]. However, the mathematical expression should be modified in order to satisfy the practical application condition.

In this study, computer-aided design and manufacturing (CAD / CAM) technology were applied to develop and produce bipolar plates composed of type 304 stainless steel for DMFC application. Surface modification of the 304 stainless steel was made by electroless Au-plating. Methanol crossover from the anode 
to the cathode through the Nafion ${ }^{\circledR}$ PEM detrimentally influenced the performance of direct methanol fuel cells. The methanol crossover rate of PEM, the efficiency of DMFC and the amount of methanol electro-oxidation at cathode side were estimated by measuring the transient voltage and current at the DMFC when methanol was introduced into the anode.

\section{Mathematical}

Before carrying out mathematical analysis, the following terms must be defined. MT: total amount of methanol charged (mole); Mao: amount of methanol electro-oxidized at anode side (mole); Mmo: amount of bipolar plates corrosion oxidation at anode side (mole); Mco: amount of crossover methanol electro-oxidized at cathode side (mole); Ef: efficiency of DMFC (\%); RC: crossover rate (mol cm-2 s-1); t: time required for electro-oxidation current to fall from I to zero (s); A: active area of electro-oxidation (cm2 ); I: current (A); n: number of electrons exchanged; F: Faraday's constant (96480A s mol-1).

A relatively easy method for estimating the methanol crossover rate of proton exchange membrane (PEM) and the efficiency of direct methanol fuel cell (DMFC) has already been proposed [10]. However, the mathematical expression must be modified in order to be using this method under in the practical application conditions; the modified equations are expressed as follows:

$M_{T}-M_{a_{o}}-M_{T} \times\left(1-E_{f}\right)-R_{c} \times t \times A=0$

where,

$E_{f}=\frac{M_{a_{o}}}{M_{T}-M_{c o}} \times 100 \%$

The net charge quantity during the operating of a direct methanol fuel cell when methanol is introduced into the anode can be expressed by the following equation,

$\int I d t=6 F\left(M_{a_{o}}-M_{c o}\right)+2 F M_{m o}$

at the right hand side of Eq. (3), the first term, , stands for the net oxidation charge quantity of methanol on the anode side and the amount of methanol crossover on the cathode side. The second term, , indicates the corrosion charge quantity of the metal bipolar plates on the anode side. In four experiments under identical operating conditions, but with different charging volumes of methanol solution, Eq. (1) becomes the following simultaneous equations:

$$
\left\{\begin{array}{l}
M_{T 1}-M_{a_{o 1}}-M_{T 1} \times\left(1-E_{f}\right)-R_{c} \times t_{1} \times A_{1}=0 \\
M_{T 2}-M_{a_{o 2}}-M_{T 2} \times\left(1-E_{f}\right)-R_{c} \times t_{2} \times A_{2}=0 \\
M_{T 3}-M_{a o 3}-M_{T 3} \times\left(1-E_{f}\right)-R_{c} \times t_{3} \times A_{3}=0 \\
M_{T 4}-M_{a o 4}-M_{T 4} \times\left(1-E_{f}\right)-R_{c} \times t_{4} \times A_{4}=0
\end{array}\right.
$$

After rearranging, we get:

$$
\left\{\begin{array}{l}
M_{T 1} \times E_{f}-R_{C} \times t_{1} \times A_{1}+\frac{1}{3} M_{m o}-M_{C O}=\frac{\int_{0}^{t_{1}} I_{1} d t}{6 F} \\
M_{T 2} \times E_{f}-R_{C} \times t_{2} \times A_{2}+\frac{1}{3} M_{m o}-M_{C O}=\frac{\int_{0}^{t_{2}} I_{2} d t}{6 F} \\
M_{T 3} \times E_{f}-R_{C} \times t_{3} \times A_{3}+\frac{1}{3} M_{m o}-M_{C O}=\frac{\int_{0}^{t_{3}} I_{3} d t}{6 F} \\
M_{T 4} \times E_{f}-R_{C} \times t_{4} \times A_{4}+\frac{1}{3} M_{m o}-M_{C O}=\frac{\int_{0}^{t_{4}} I_{4} d t}{6 F}
\end{array}\right.
$$


Even though of there are four unknown parameters Mmo ,Mco, Ef and RC in Eq.(5) however, the value of parameter Mmo can be set to zero since the corrosion current of the stainless steel plate is much lower when the stainless steel bipolar plate used on the anode side for DMFC. In this study, Eq. (5) can be reduced as follows:

$$
\left\{\begin{array}{l}
M_{T 1} \times E_{f}-R_{C} \times t_{1} \times A_{1}-M_{C O}=\frac{\int_{0}^{t_{1}} I_{1} d t}{6 F} \\
M_{T 2} \times E_{f}-R_{C} \times t_{2} \times A_{2}-M_{C O}=\frac{\int_{0}^{t_{2}} I_{2} d t}{6 F} \\
M_{T 3} \times E_{f}-R_{C} \times t_{3} \times A_{3}-M_{C O}=\frac{\int_{0}^{t_{3}} I_{3} d t}{6 F}
\end{array}\right.
$$

The above simultaneous equations can be transformed into matrix form as

$\mathrm{A} x=\mathrm{b}$

Where

$\mathrm{A}=\left[\begin{array}{lll}M_{T 1} & -t_{1} \times A_{1} & -1 \\ M_{T 2} & -t_{2} \times A_{2} & -1 \\ M_{T 3} & -t_{3} \times A_{3} & -1\end{array}\right] \quad \mathrm{X}=\left[\begin{array}{l}E_{\gamma} \\ R_{e} \\ M_{e s}\end{array}\right]$

And

$$
\mathrm{b}=\left[\begin{array}{l}
\frac{\int_{0}^{t_{1}} I_{1} d t}{6 F} \\
\frac{\int_{0}^{t_{2}} I_{2} d t}{6 F} \\
\frac{\int_{0}^{t_{3}} I_{3} d t}{6 F}
\end{array}\right]
$$

The simultaneous equations can be easily solved by the inverse matrix:

$$
X=A^{-1} \boldsymbol{b}
$$

The methanol crossover rate of PEM (Rc), the efficiency of DMFC (Ef), and the amount of methanol electro-oxidation on the cathode side can be easily computed from Eq. (8) using Microsoft Excel@.

\section{EXPERIMENTAL}

\subsection{Computer-aided design and manufacturing of the DMFC device}

The direct methanol fuel cell device consists of two supporting plates (PMMA), stainless steel bipolar plates and a membrane electrode assembly (MEA). The CAD / CAM software I-DEAS was employed to conduct 3D solid modeling design, as shown in Fig. 1. Bipolar plates were designed with the mirror symmetry which enables the positive and negative stacking. All the holes on the plate should be aligned with each other after stacking, as shown in Fig. 2. Stainless steel bipolar plates were manufactured by a Japanese Mitsubishi laser cutting machine (3500W ML3015LVPlus).

The DMFC device has two supporting plates. The first plate has a $50 \mathrm{~mm} \times 50 \mathrm{~mm}$ opening square slot for air inlet which can be made entirely by laser cutting. The other plate, with a $50 \mathrm{~mm} \times 50 \mathrm{~mm} \times 7 \mathrm{~mm}$ square slot, acts as methanol fuel tank. A groove was made around the square slot for placing a rubber ring to prevent leakage of methanol fuel. There are two holes at the top of square slot for injecting methanol fuel. These slots 
also act as an air outlet. The CAD/CAM software SmartCAM was employed to process the tool path planning and manufacturing simulation.

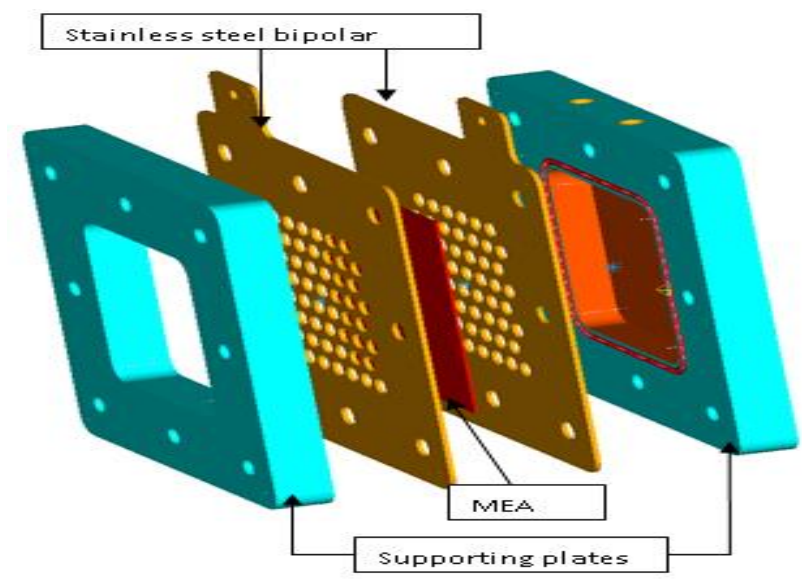

Figure.1. 3D solid modeling design of DMFC device: supporting plates, stainless steel bipolar plates and MEA.

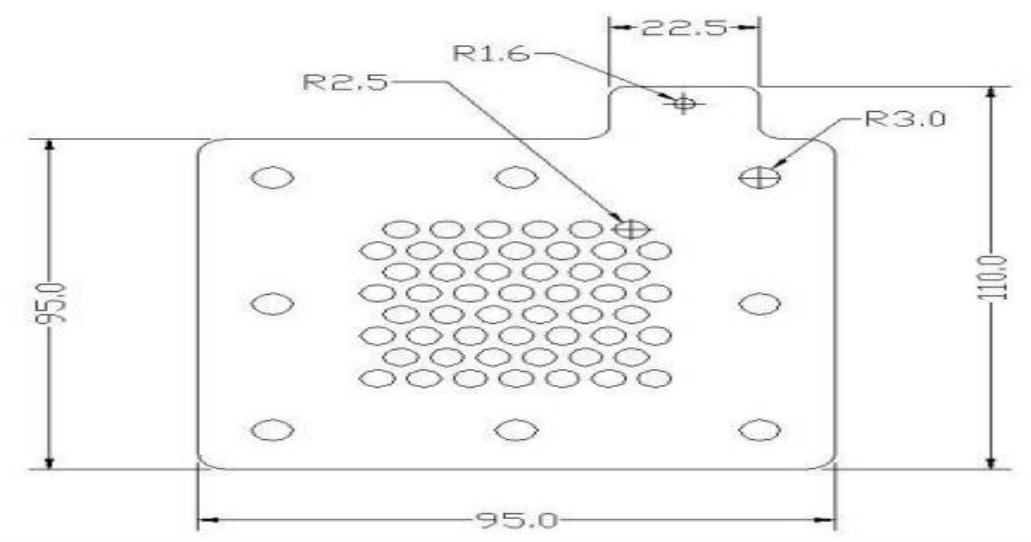

Figure.2. Dimensions of bipolar plate

\subsection{Electroless gold - plating}

In this study, type 304 stainless steel plates were chosen as the bipolar plates of a DMFC. Before electroless plating, the stainless steel plates were polished on 200, 600, 800, 1000 and 1200 grit silicon carbide papers and a final polish with $1.0 \mu \mathrm{m}$ alumina powder. The polished plates were thoroughly cleaned with distilled water in an ultrasonic bath for $15 \mathrm{~min}$ and dried with air before passing through the procedure of the eletroless method. The operating conditions and steps of this method are illustrated in Fig. 3.

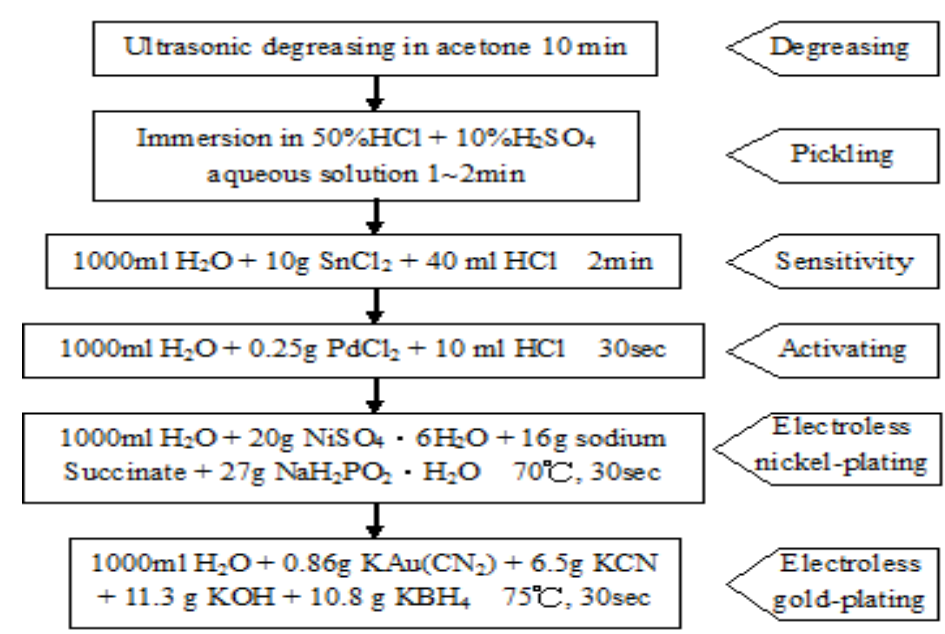

Fig.3. Flow chart of preparing the gold - plating by an electroless method. 


\subsection{Cell performance testing}

The experimental system uses a DMFC that includes an anode chamber for the electrochemical oxidation of the methanol, a cathode chamber for the electrochemical reduction of oxygen and a membrane electrode assembly (MEA) arranged between the anode and the cathode. On the anode side, the bare and coated SS304 stainless steels served as anode polar plates, respectively. On the cathode side, the bare SS304 stainless steel served as cathode polar plate only. A load unit was connected to the DMFC. An aqueous solution of the methanol was fed to the anode chamber while the load unit was operated at $10 \Omega$ in a loading state, enabling the methanol to crossover to the cathode, where it was oxidized. The transient voltage and current were measured using a digital-meter and the methanol crossover rate, the efficiency of direct methanol fuel cell (DMFC) and the amount of methanol electro-oxidation on the cathode side were determined from the transient current analysis. In this work, the membrane electrode assembly (MEA) was made according to the method proposed by Kin et al. [10].

The fuel chamber $(0.7 \mathrm{~cm}$ thick with an area of $25 \mathrm{~cm} 2)$ was filled with $1.1 \mathrm{~cm} 3,3.3 \mathrm{~cm} 3$ and $4.4 \mathrm{~cm} 3$ 10 vol.\% aqueous methanol solution, for the first, second and third measurements, respectively. All tests were performed at an ambient temperature of $25^{\circ} \mathrm{C}$ and at atmospheric pressure. The voltage and current of the DMFC were monitored for approximately $36 \mathrm{~h}$ to ensure a stable approach to zero current.

\section{RESULTS AND DISCUSSION}

Figs. 4 - 7 show the changes of transient voltage and current of the DMFC with time after each measurement was performed at a different charging volume $(1.1 \mathrm{~cm} 3,3.3 \mathrm{~cm} 3$ and $4.4 \mathrm{~cm} 3)$ with a particular fuel solution of $10 \mathrm{Vol} \%$ methanol in water when Au-coated and uncoated SS304 stainless steels served as anode polar plates, respectively. We compared the cell voltage and current response of the DMFC with the Aucoated and uncoated stainless steels serving as anode polar plates, respectively. When the Au-coated stainless steel served as the anode polar plate, we found higher cell voltage and current values than in the case of the uncoated stainless steel. These values can be attributed to the decreased crossover rate (Rc), increased efficiency (Ef) and decreased amounts of methanol electro-oxidation on the cathode side (Mco ), which are derived below.

The data in Table 1 were used to calculate the crossover rate $\left(R_{c}\right)$, the efficiency $\left(E_{f}\right)$ and the amount of methanol electro-oxidation of the cathode side $\left(M_{c o}\right)$ at various fuel charging volumes in the three tests. Through the transient current results and mathematical analysis of Eq. (8) computed using Microsoft Excel®, the crossover rates $\left(R_{c}\right)$, efficiency $\left(E_{f}\right)$ and amounts of methanol electro-oxidation on the cathode side $\left(M_{c o}\right)$ are determined to be $5.9 \mu \mathrm{mol} \mathrm{cm} \mathrm{cr}^{-1}$ and $10.4 \mu \mathrm{mol} \mathrm{cm} \mathrm{cr}^{-1}, 22.1 \%$ and $17.8 \%, 27$ and $32.5^{\mathrm{mmol}}$ as shown in Table 2 for the coated and uncoated anode polar plates, respectively. It is obvious that the crossover rate $\left(R_{c}\right)$ of the coated anode polar plate decreased by about $43 \%$, the efficiency $\left(E_{f}\right)$ increased by about $4.3 \%$ and the amount of methanol electro-oxidation on the cathode side $\left(M_{c o}\right)$ decreased by about $17 \%$ in comparison to the results of the uncoated anode polar plate. These results reveal the effects of surface modification on methanol crossover, efficiency and the amount of methanol electro-oxidation on the cathode side of a DMFC.

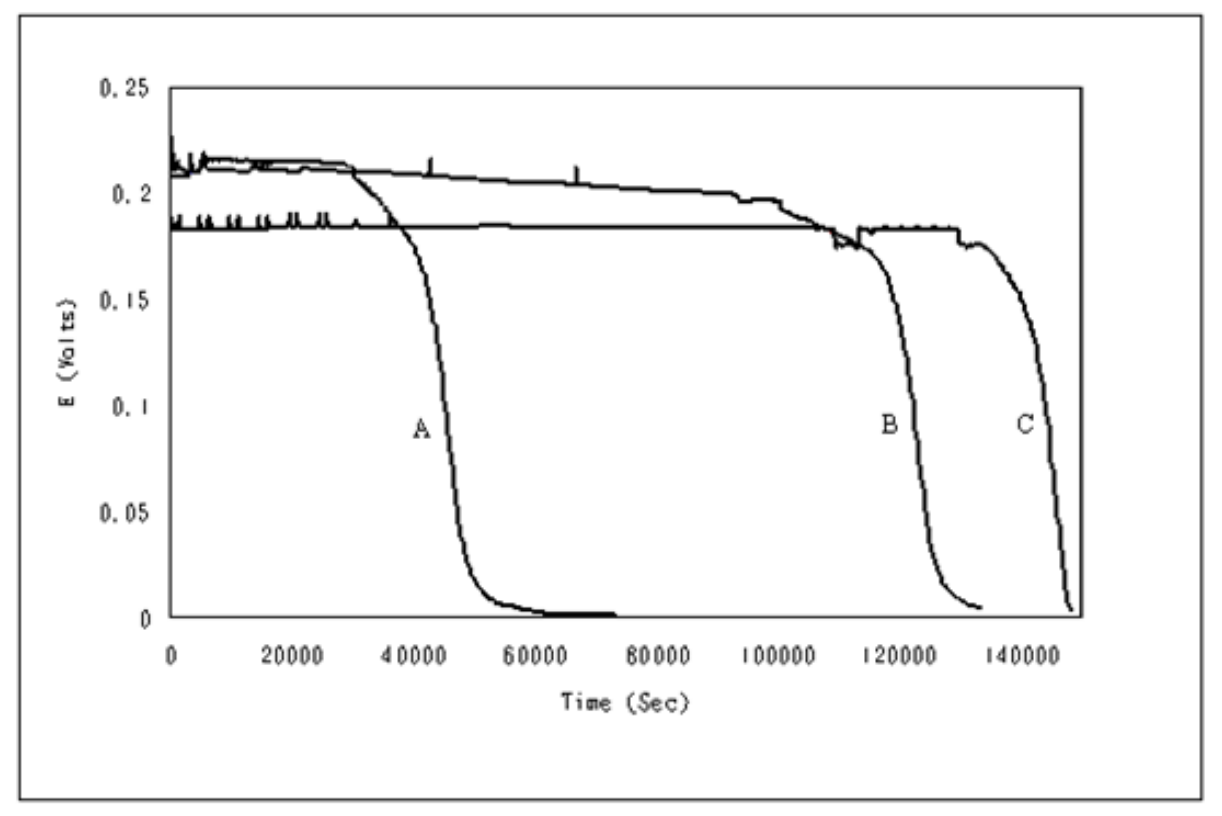

Figure. 4. Voltage transients monitored during electro-oxidation using 10 vol. \% methanol solution for DMFC with Au-coated anode polar plate: (A) $1.1 \mathrm{~cm} 3$, (B) $3.3 \mathrm{~cm} 3$, and (C) $4.4 \mathrm{~cm} 3$ 


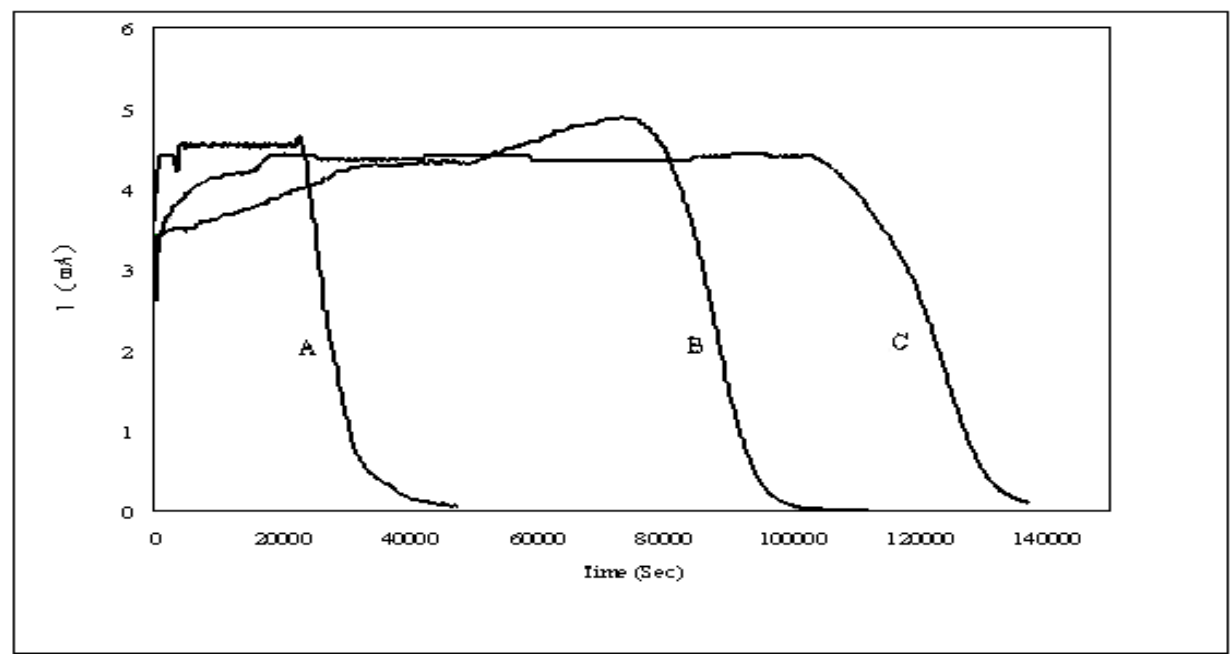

Figure. 5. Current transients monitored during electro-oxidation using 10 vol. \% methanol solution for DMFC with Au-coated anode polar plate : (A) $1.1 \mathrm{~cm} 3$, (B) $3.3 \mathrm{~cm} 3$, and (C) $4.4 \mathrm{~cm} 3$

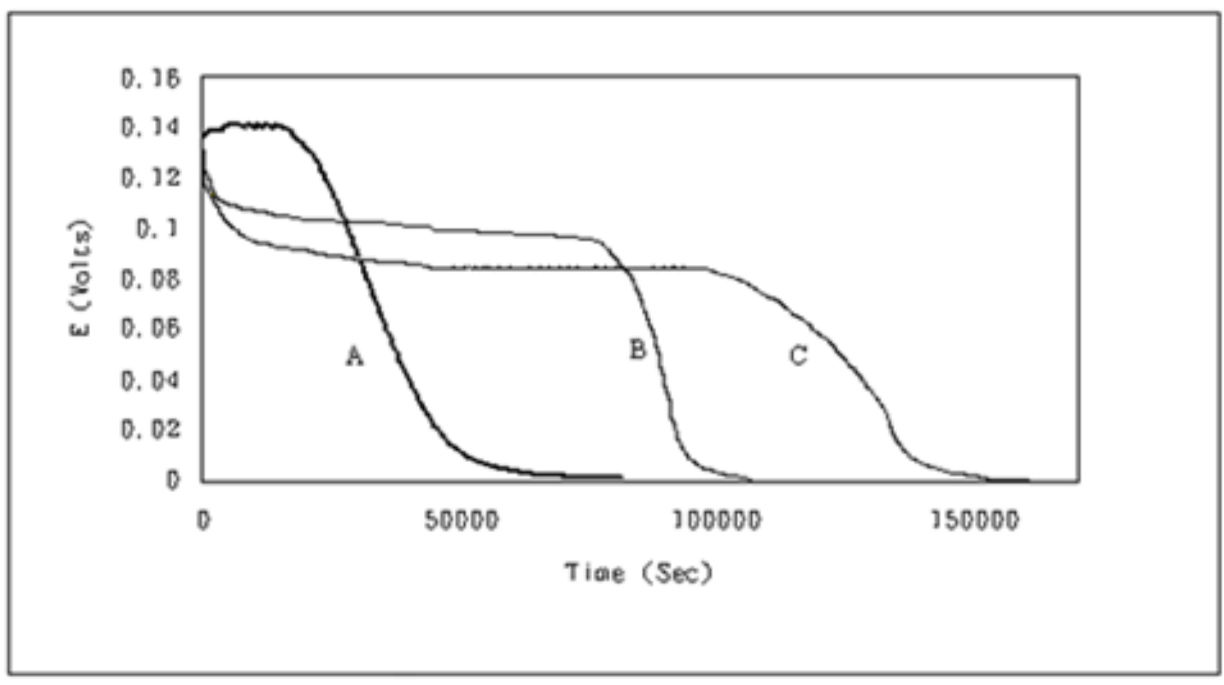

Figure. 6. Voltage transients monitored during electro-oxidation using 10 vol. \% methanol solution for DMFC with uncoated anode polar plate: (A) $1.1 \mathrm{~cm} 3$, (B) $3.3 \mathrm{~cm} 3$, and (C) $4.4 \mathrm{~cm} 3$

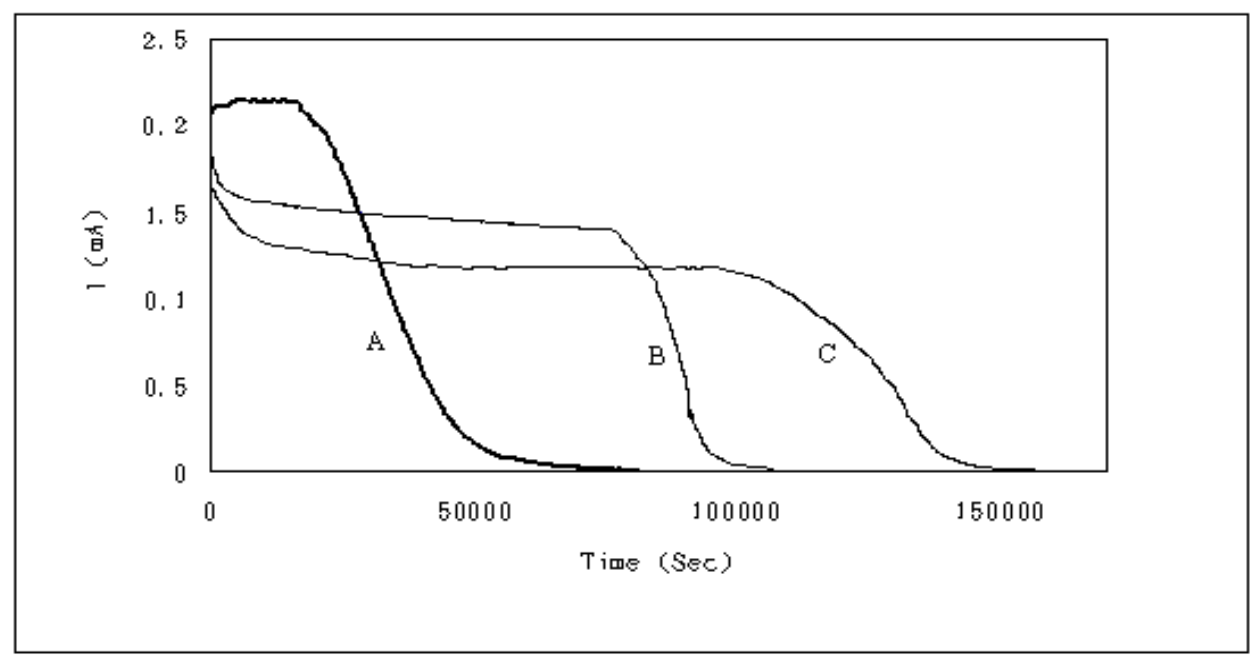

Figure. 7. Current transients monitored during electro-oxidation using 10 vol. $\%$ methanol solution for DMFC with uncoated anode polar plate: (A) $1.1 \mathrm{~cm} 3$, (B) $3.3 \mathrm{~cm} 3$, and (C) $4.4 \mathrm{~cm} 3$ 
Table 1

Parameters.

\begin{tabular}{|c|c|c|c|}
\hline Known parameters & Test 1 & Test 2 & Test 3 \\
\hline Methand concentration (vol. $\%$ ) & 10 & 10 & 10 \\
\hline Active area, $A\left(\mathrm{~cm}^{2}\right)$ & 1.37 & 4.32 & 5.1 \\
\hline Methand charged $\left(\mathrm{cm}^{2}\right)$ & 1.1 & 3.3 & 4.4 \\
\hline Methand charged, $\mathrm{M}_{\tau}$ (mmol) & 2.7 & 8.2 & 10.9 \\
\hline \multicolumn{4}{|l|}{ Measured parameters } \\
\hline T ine of crossover, $t$ (h), as the anode polar plate with Au coating condition & 8.3 & 262 & 36 \\
\hline $\begin{array}{l}\text { Time of crossover , } t(h) \text {. as the anode polar plate without Au coating } \\
\text { condition }\end{array}$ & 59 & 21 & 26.8 \\
\hline
\end{tabular}

Table 2

Analysis results.

\begin{tabular}{|c|c|}
\hline Analy is results & \\
\hline $\begin{array}{l}\text { Amount of crossover methanol electro-cr idized at cathode side. . } M_{c e}(m m o \text { ). as } \\
\text { the anode polar plate with Au coeting }\end{array}$ & 27 \\
\hline $\begin{array}{l}\text { Am ount of crossover methanol electro-cr idation at cathode side, } M_{-}(m m o l) \text {, as } \\
\text { the anode polar plate without Aus coating }\end{array}$ & 325 \\
\hline $\begin{array}{l}\left.\text { Crossover rate, } R_{c} \text { (thol } \mathrm{cm}^{-2} \mathrm{~h}^{-1}\right) \text {, as the anode polar plate with Aul coating } \\
\text { condition }\end{array}$ & $5.9 \mathrm{E}-6$ \\
\hline $\begin{array}{l}\text { Crossover rate, } R_{-}\left(\text {trol } \mathrm{cm}^{-2} \mathrm{~h}^{-1}\right) \text {, as the anode polar plate without Au coating } \\
\text { condition }\end{array}$ & $104 \mathrm{E}-6$ \\
\hline Efficiency. $E_{1}(\%)$ as the anode polar plate with Aucoating condition & $22.1 \%$ \\
\hline Efficiency, $E_{\gamma}(\%)$, as the anode polar plate without Aul coating condition & $17.8 \%$ \\
\hline
\end{tabular}

\section{CONCLUSION}

In this study, a stainless steel bipolar plate was designed and fabricated using computer-aided design and manufacturing (CAD / CAM) technology. Surface modification of the stainless steel bipolar plate was made by the electroless Au-plating method. The methanol crossover rate of the proton exchange membrane (PEM) decreased by about $43 \%$, the efficiency of DMFC increased by about $4.3 \%$ and the amount of methanol electrooxidation on the cathode side was decreased by about $17 \%$, in comparison to the results of the uncoated anode polar plates. These findings were determined by transient current and mathematical analysis.

\section{REFERENCES}

[1] J. Kim, S.M. Lee, S. Srinivasan, et al., "Modeling of proton exchange membrane fuel cell performance with an empirical equation,"” Journal of Electrochemistry Society, Vol. 142, No.8, 1995, pp.2670-2674.

[2] J.H. Lee, T.R. Lalk, "Modeling fuel cell stack systems," Journal Power Sources, Vol. 73, 1998, pp. 229-241.

[3] W. Yoon, X. Huang, P. Fazzino, K. L. Reifsnider, M. A. Akkaoui,"Evaluation of coated metallic bipolar plates for polymer electrolyte membrane fuel cells" Journal of Power Sources, Vol. 179, 2008, No.1 ,pp. 265-273.

[4] A. Kumar, M. Ricketts, S. Hirano,"Ex situ evaluation of nanometer range gold coating on stainless steel substrate for automotive polymer electrolyte membrane fuel cell bipolar plate" Journal of Power Sources, Vol.195, 2010, No.5, pp.1401-1407.

[5] Jay T. Pukrushpan, G.Anna, "Modeling and control for PEM fuel cell stack system, in: Proceeding of the American Control Conference, Anchorage, AK", 2002, pp. 3117-3122.

[6] S. R. Narayanan, A. Kindler, B. Jeffries-Nakamura, W. Chun, H. Frank, M. Smart, T. I. Valdez, S. Surampudi, G. Halpert, J. Kosek , C. Cropley, Proceedings of Annual Battery Conference on Applications and Advances ,Vol. 11, 1996, 113.

[7] J.C. Amphlett, R.F. Mann, B.A. Peppley, "A practical PEM fuel cell model for simulating vehicle power sources, battery conference on applications and advances, in: Proceedings of the tenth annual"1995, pp. 221-226.

[8] N. Munichandraiah, K. McGrath, G. Prakash, R. Aniszfeld, G. Olah, "A potentiometric method of monitoring methanol crossover through polymer electrolyte membranes of direct methanol fuel cells" Journal of Power Sources, Vol.117, No1-2, 2003, 98-101.

[9] Jiahua Han, Hongtan Liu, "Real time measurements of methanol crossover in a DMFC" Journal of Power Sources, Vol, 164,No.1, 2007, pp. 166-173.

[10] T. H. Kin, W. Y. Shieh, C. C. Yang, George Yu,"Estimating the methanol crossover rate of PEM and the efficiency of DMFC via a current transient analysis Pages" Journal of Power Sources, Vol. 161,No.2, 2006, pp.1183-1186. 